\title{
Sedimentary Transport Influences on Diagenetic Processes at the Amazon Continental Shelf, Brazil
}

\author{
Fabio Aprile $^{1^{*}}$, Gilmar W. Siqueira ${ }^{2}$, Assad Darwich $^{3}$ and Georg Irion ${ }^{4}$ \\ ${ }^{1}$ Western of Pará Federal University, 68040-070 PA, Brazil. \\ ${ }^{2}$ Pará Federal University, 66075-100 PA, Brazil. \\ ${ }^{3}$ National Institute of Research in Amazonian, 69060-001 AM, Brazil. \\ ${ }^{4}$ Senckenberg am Meer Institute, Suedstrand 40, 26382 Wilhelmshaven, Germany.
}

Authors' contributions

All authors participated of the samples collection, date and statistical analysis and wrote the first draft of the manuscript.

Article Information

DOI: 10.9734/JGEESI/2019/v20i430113 Editor(s):

(1) Dr. Ioannis K. Oikonomopoulos, Core Laboratories LP., Petroleum Services Division, Houston Texas, USA.

Reviewers:

(1) Umo, Ikpong Sunday, Alvan Ikoku Federal College of Education, Nigeria.

(2) R. García Giménez, Universidad Autónoma de Madrid, Spain. Complete Peer review History: http://www.sdiarticle3.com/review-history/48586

Original Research Article

Received 07 February 2019

Accepted 15 April 2019

Published 23 April 2019

\begin{abstract}
This research aimed to correlate the sedimentary transport with the diagenetic processes in the coastal zone and Amazon Continental Shelf (ACS). Physical and physical-chemical parameters, trace element contents $(\mathrm{Cr}, \mathrm{Pb}, \mathrm{Ni}, \mathrm{Zn}$ and $\mathrm{Hg})$, and $\mathrm{O}_{2}, \mathrm{CO}_{2}$ and iron flux were determined in sediment and pore water. Sedimentary incubation (96 hours) and algorithms were applied to determine the variation of the activity coefficient $(\Delta \mathrm{I})$ and ionic strength $\left(\mathrm{F}_{\mathrm{i}}\right)$ of the predominant chemical species, and to estimate the net production and mineralization of the organic matter $\left(\Delta \mathrm{CO}_{2 \mathrm{~T}}\right)$ in the system. There are not many studies applying incubation tests to identify the diagenetic processes, especially in fluvial-marines sediments. The results showed a strong zonation associated to the transport and deposition processes, influenced mainly by the grain-size and texture of sediment and fluvial streams. The distribution of trace elements followed the trend of the sedimentary pattern, with higher levels of metals in the deposits of clay minerals and organic matter. A factor of weight $\left(F_{w}\right)$, calculated to establish the degree of importance of each parameter under the distribution and mobility of trace elements, suggests that the mobility of $\mathrm{Cr}, \mathrm{Ni}$ and $\mathrm{Zn}$ is controlled by depth, clay and organic compounds contents, and concentration of dissolved oxygen.
\end{abstract}


The vertical flow of $\mathrm{O}_{2}$ and $\mathrm{CO}_{2}$ and the $\mathrm{Fe}^{2+} / \mathrm{Fe}^{3+}$ ratio in the pore water suggest a predominance of organic matter oxidation in the sedimentary layer between 0.0 and $0.2 \mathrm{~m}$, with partially anaerobic mineralization of the sediments below $0.4 \mathrm{~m}$. Increases in trace element concentrations were observed in iron reduction zones, indicating processes of desorption of oxides and hydroxides of Fe and mineralization of organic matter. The extrapolation of the results of the incubation test to the studied system allowed to establish three hypotheses related to the diagenetic processes: 1) the flow of marine currents may be allowing the aerobic oxidation in the sandy sediments, with the nitrification route more accentuated than the ammonification route; 2 ) in the region of the coastal zone and inner continental shelf the routes of oxidation and reduction may be alternating according to the physical-chemical factors and seasonality; 3 ) in the coastal zone and inner shelf the net mineralization rate exceeded the net production rate of the organic matter $\left(\Delta \mathrm{CO}_{2 T}>0\right)$.

Keywords: Pore water; mineralization; net productivity; sedimentary characterization; diagenetic processes; Amazon continental shelf.

\section{INTRODUCTION}

The sedimentary transport regime analysis is much applied in association with geochemistry in quantitative studies, revealing areas of cumulative tendency or sedimentary dispersion. Studies have demonstrated that the sedimentation rate associated with microbiological activity, organic carbon content and seasonal events affect the concentration of dissolved chemical species directly in the sediments [1,2], especially in water [3,4], which justifies the influence of sedimentary transport on the diagenetic regime, with particular emphasis on quantifying the seasonal rates and spatial patterns of carbon remineralization.

Pore water can be interpreted as a physicalchemical and biological transition phase between what happens in the water and sediment compartments. This suggests a complexity of factors and processes acting jointly in the genesis and flow of chemical species, either by diffusion, advection, precipitation and/or dissolution of minerals, metallic adsorption/desorption, bioturbation, production or mineralization of organic matter [4-6]. The composition (clay and organic matter), physical (porosity) and physical-chemical properties $(\mathrm{pH}$ and alkalinity) of the sediments influence in the diffusion and transport of the chemical species in the pore water [5-7], either by vertical or horizontal movements.

In the region between the Amazon and Pará mouths, and the Amazon Continental Shelf (ACS; Fig. 1), the sedimentary dynamics is the largest in the world, both in volume and dispersion area. The distributions of minerals in ACS sediments [8], as well as organic and inorganic components, including trace elements
[9], are of unequaled proportions to any other fluvial-marines system on the planet. Fluvialmarines currents play an important role in this sedimentary dynamics, acting individually or together, and seasonally in the Amazonian system. The balance between the erosion, transport and sedimentation processes interferes with the volume of sediments and, consequently, with the concentration of chemical species in the fluvial-marine system. The Amazon River presents the highest suspended solids load transported in the world, about $1.2 \times 10^{9}$ metric tons/year of sedimentary debris to its lower reaches [10], and that once reaching the continental shelf will submit to a coastal dynamic, mainly by the influence of the North Brazilian Current (NBC) along the American continent. Sedimentary load representing $\sim 3 \%$ of the global riverine particle flux, accumulates off the river mouth in Brazilian coastal waters as deltaic mud deposits having a northwest trending strike [11].

Diagenetic reactions and sediment-water exchange processes occurring in deposits of the ACS determining the eventual influence of the Amazon on a range of marine elemental cycles and characteristics of the resulting sediment record [12]. The diagenetic processes involve the genesis of chemical species with consequent alteration in these compositions in the environment. Among the processes involved in diagenesis, the net production and mineralization of organic matter have been highlighted in geochemical studies, as they interfere in the flow and balance of gases $\left(\mathrm{CO}_{2}, \mathrm{O}_{2}, \mathrm{CH}_{4}, \mathrm{H}_{2} \mathrm{~S}\right.$ and $\mathrm{SO}_{4}{ }^{2-}$ ) in the water and sediment compartments, in the metallic mobilization, and in the aerobic and anaerobic benthic microbial productivity.

This research aimed to correlate the sedimentary transport with the diagenetic processes in the 
area between the coastal zone and outer shelf of the ACS. For this, 1) the distribution and flow of trace elements $(\mathrm{Cr}, \mathrm{Pb}, \mathrm{Ni}, \mathrm{Zn}$ and $\mathrm{Hg}) ; 2$ ) the profile of the vertical flow of $\mathrm{O}_{2}$ and $\mathrm{CO}_{2}$ in the pore waters, relating them to the iron redox potential $\left(\mathrm{Fe}^{2+}\right.$ and $\left.\mathrm{Fe}^{3+}\right)$; and 3) net production and mineralization of organic matter, identifying the dominant pathway in the pore water system were determined and/or estimated.

\section{STUDY AREA}

The study has been conducted in the Amazon River, nearby coastal zone (CZ) and Amazon Continental Shelf - ACS $\left(47^{\circ} 52^{\prime} \mathrm{W}-4^{\circ} 19^{\prime} \mathrm{N}\right.$ and $51^{\circ} 04^{\prime} \mathrm{W}-2^{\circ} 16^{\prime} \mathrm{S}$ ) between Orange Cape (State of Amapá) and Pará River mouth (State of Pará, Fig. 1). It is a dynamic region, influenced by the meeting of continental waters with the Atlantic Ocean on influence at the Equatorial North Current (ENC) and NBC. There is also interference from atmospheric forces as the
Intertropical Convergence Zone (ICZ), generating trade winds and rainfall, which determining the climatic seasons and the hydrological pattern of Amazonian rivers [8]. This complex system of water circulation influences sediment transport and deposition, acting in a selective way to separate the sedimentary fractions and the content of organic material by zonation in the coastal zone and ACS. The climate of the region is "Am" hot and constantly humid (monsoon climate) for Marajó Bay, and 'Af' equatorial for Amazon and Pará mouths, with mean temperature of $28^{\circ} \mathrm{C}$ and rainfall exceeding 2000 $\mathrm{mm} /$ year, especially between the months of December and February. The Amazon coastal zone includes diverse ecosystems as mangroves, dunes, coastal forests, freshwater coastal, estuaries and river deltas with great aquatic and terrestrial biodiversity associated. Descriptions of the study area and sedimentary patterns can be found in many researchers $[8,9,11,13]$.

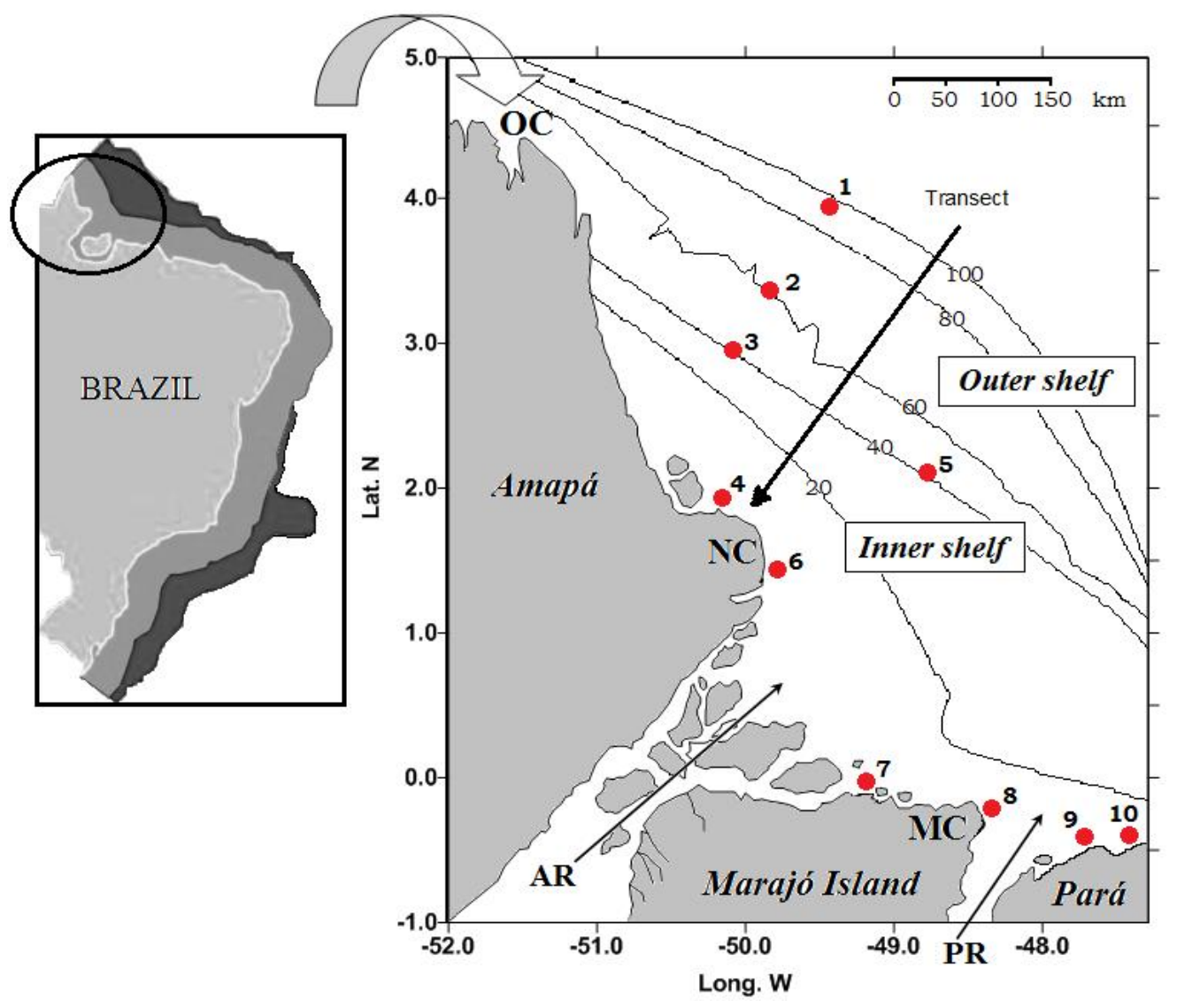

Fig. 1. Map of the ACS and coastal zone between orange cape (OC) and Pará River mouth. Details of the shelf - coastal zone vector $1-4$ (transect)

Legend: $N C=$ North Cape; $M C=$ Maguari Cape; $A R=$ Amazon River; $P R=$ Pará River; isobaths in meters 


\section{MATERIALS AND METHODS}

Physical-chemical, water column hydrography and sedimentary load measurements were made following the regime of seasonality in the region. The bathymetric lines (isobaths) showed in the Fig. 1 were obtained from probe eco-bathymetry and for consultations to nautical charts. A tendency line (exponential fitting curve) with the respective differential equations was determined for the bathymetric profile, with orientation axis from the coastal zone in direction to outer shelf. The sediment samplings, however, were performed during the months of lowest flow (May and June) in the Amazon and Pará rivers and at the ACS. Samples of bottom sediments (0.0 - 0.5 $\mathrm{m})$ were obtained between the 5 and $100 \mathrm{~m}$ isobaths using Van-Veen sampler $\left(A=682 \mathrm{~cm}^{2}\right)$ to the bottom sediments, and box-core sampler $\left(A=177 \mathrm{~cm}^{2}\right)$ to the vertical samples. The sediment samples were stored in plastic bags and kept in freezer at $-5^{\circ} \mathrm{C}$ until the analysis. Vertical samples were used to determine the $\mathrm{pH}$, salinity (dS/m) and dissolved oxygen (DO $\mu \mathrm{mol} / \mathrm{L})$ in the pore water.

At chemistry laboratories at Pará Federal University (UFPA) and National Institute of Research in Amazonian (INPA), the sediment samples used for geochemical analysis were fractionated, oven dried $\left(45 \pm 0.5^{\circ} \mathrm{C}\right)$ and homogenized, sieved and pulverized until very fine sand fraction $(125-63 v f s \mu \mathrm{m})$. The $\mathrm{pH}$ of the samples was neutralized with $2 \mathrm{M} \mathrm{NH} \mathrm{NH}_{4} \mathrm{OH}$ solution and $30 \mathrm{~mL}$ of Mil-Q water followed by titration of the chloride, to ensure no interference of the $\mathrm{Cl}$ - analyzes. For the incubation test, fresh samples were homogenized and stored in polyethylene bottles with a sealed acrylic lid. DO and $\mathrm{CO}_{2}$ were determined with probes and analytical methods (titration) from the extraction of the pore water, and profiles of oxygen (DO $\mu \mathrm{mol} / \mathrm{L})$ and total $\mathrm{CO}_{2}\left(\Sigma \mathrm{CO}_{2} \mathrm{mmol} / \mathrm{L}\right)$ were established in the vertical layer of the sediments sampled for the vector $1-4$ (Fig. 1).

Grain-size analysis was determined by the gravimetric method [14]. Organic matter (OM) was determined by hot acidic extraction with excess hydrogen peroxide $(30 \%)$ at $100^{\circ} \mathrm{C}$ [15]. The organic carbon content (OC) was determined by the Walkley-Black method [16], where the organic carbon of the sample is oxidized to $\mathrm{CO}_{2}$ with potassium dichromate $\left[\mathrm{K}_{2} \mathrm{Cr}_{2} \mathrm{O}_{7}\right]$ and concentrated sulfuric acid $\left[\mathrm{H}_{2} \mathrm{SO}_{4}\right]$. The chromium of the extractive solution is reduced to $\mathrm{Cr}^{3+}$, and the excess of potassium dichromate is titrated by the ammonium iron (II) sulfate $\left[\left(\mathrm{NH}_{4}\right)_{2} \mathrm{Fe}\left(\mathrm{SO}_{4}\right)_{2} \cdot 6 \mathrm{H}_{2} \mathrm{O}\right]$. The calculation is done by applying equation 1 [14]. Free $\mathrm{CO}_{2}$ $\left(\mathrm{CO}_{2 \mathrm{~L}} \mathrm{mmol} / \mathrm{L}\right)$ and total $\mathrm{CO}_{2}\left(\mathrm{CO}_{2 \mathrm{~T}} \mathrm{mmol} / \mathrm{L}\right)$ were determinates with probe and also obtained analytically by titrimetric method $4500-\mathrm{CO}_{2} \mathrm{~A}$ and $D$ [17]. The titration was performed potentiometrically with $\mathrm{NaOH}$ to bring the sample to $\mathrm{pH} 8.3$ and $\mathrm{HCl}$ to $\mathrm{pH} \mathrm{4.3.} \mathrm{From} \mathrm{the} \mathrm{results,}$ the carbonate and bicarbonate alkalinities also were calculated. Inorganic carbon (IC) was calculated from the amount of total $\mathrm{CO}_{2}$ per molar transformation [15].

$$
O C=0.06 V(40-V a \times f)
$$

Where: OC $(\mathrm{g} / \mathrm{kg}) ; \mathrm{V}=$ volume of potassium dichromate and $\mathrm{V}_{\mathrm{a}}=$ volume of ammonium iron(II) sulfate consumed in the reaction; $f=40$ / volume of ammonium iron(II) sulfate used in the blank titration; $0.06=$ correction factor.

Trace metals $\mathrm{Cr}, \mathrm{Pb}, \mathrm{Ni}$ and $\mathrm{Zn}(\mathrm{mg} / \mathrm{kg})$ were extracted using mixture $\left[\mathrm{HNO}_{3}+\mathrm{HCl}\right]: \mathrm{HClO}_{4}: \mathrm{HF}$ (Merck 2:1:1) in an open system and determined in a flame atomic absorption spectrometry Shimadzu AA 6800 (Standard Method 3111B modified) [17]. Total $\mathrm{Hg}(\mathrm{ng} / \mathrm{g})$ was extracted adding dry sediment and $\mathrm{V}_{2} \mathrm{O}_{5}(1: 1)$ and after a solution of $\mathrm{HCl}: \mathrm{HNO}_{3}: \mathrm{H}_{2} \mathrm{SO}_{4}$ (Merck 3:1:6) in a test tube closed, and determined in cold-vapor atomic absorption (Standard Method 3112B and 3500-HgB adapted) [17]. For analytical quality control, the recovery levels of acid digestion and determination of metals were tested using certified reference material (SRM 2710 nearshore seawater, National Research Council of Canada) analyzed in triplicate. The determinations of the total and reduced iron $\left(\mathrm{Fe}^{2+}\right)$ fractions were obtained from the methods described by Jackson [14], Silva [15]. By mass difference the $\mathrm{Fe}^{3+}$ fraction was calculated and $\mathrm{Fe}^{2+} / \mathrm{Fe}^{3+}$ ratio was established. The oxidation potential of the solid-reactive phase of the iron in the sediments was estimated by leaching wet sediment in $6 \mathrm{~N} \mathrm{HCl}$ for 15 minutes at $22^{\circ} \mathrm{C}(10: 1$ mg sediment $/ \mathrm{ml} \mathrm{HCl}$ ) and analyzing the leachate for total $\mathrm{Fe}$ and $\mathrm{Fe}^{2+}$.

The river hydrographic states were used to identify seasonal sampling times, and the respective seasonality. Sampling of the coastal zone and ACS were designed to include a range of major environmental conditions corresponding to changes in likely sedimentation patterns, Amazon River and Para River flows, trade wind stress, and influence of the Equatorial North Current and North Brazil Current (NBC). The 
study of the diagenetic processes was concentrated at the sampling sites inserted in the vector $1-4$ (Fig. 1), starting at the deepest local (site 1), near the isobath 100 meters, and ending at the coastal zone (site 4), already under influence of the river currents. The sedimentary transport regime was identified by the analysis of the tendency of space-time clustering of the sedimentary fractions. To estimate diffusive sedimentary flux, the incubation method described by Mackin and Swider [18] was used. In order to estimate potential diffuse exchange rates and the rates of net production and mineralization of organic matter, samples stored in the sealed vials were shaken vigorously for 5 minutes and then allowed to stand at $20 \pm 0.5^{\circ} \mathrm{C}$ and light/dark phases controlled for 4 days (96h). Pore water samples were removed of the sealed vials at incubation times $t_{0}=0 \mathrm{~h}$ and $t_{7}=96 \mathrm{~h}$ with a syringe to estimate $\mathrm{CO}_{2 \mathrm{~L}}$ and $\mathrm{CO}_{2 \mathrm{~T}}$ contents, according to the analytical protocols described by Silva [15], APHA [17]. Preliminary tests showed that after four days is more difficult to estimate the diffuse sedimentary flux for the adopted method as well as for the conditions at the ACS, especially in the coastal zone with high OM levels. This occurs because the DO levels after four days are very low almost imperceptible. Thus, a maximum time of measure of four days or 96 hours was established $\left(t_{0}=0 \mathrm{~h}\right.$ and $t_{7}=96 \mathrm{~h}$ in equation 4). Diffusive fluxes of the sediments were calculated from flux (vertical sampling from box core) by dividing the slope of a least squares line fit of the total mass change of a solute at time ' $t$ ' in overlying water versus elapsed incubation time by the area of the flux core. For this study the close system method was adopted for incubation tests (to see item 4.4 Sedimentary incubation). Pore water samples were collected and analyzed for $\mathrm{DO}$ and $\mathrm{CO}_{2 \mathrm{~T}}$ according to methods already decrypted. The $\mathrm{DO}$ and $\mathrm{CO}_{2}$ curves of consumption/ production in function of the time $(\Delta t)$ are determined, suggesting the speed of the reaction of the diffuse flux (slow moderate - fast). Exchange liquid flux by diffusion at the water-sediment interface can be estimated from tables according to temperature and pressure in the environment (pressure of gas diffusion). The net production is obtained from the determination of the $\mathrm{CO}_{2}$ rates in function of the time $(\Delta t)$. Using the algorithms of the software Carbmar 1 and 2, and Alcagran (Basic@) and TBasic(C) 1994) and applying equations 2 7 , the net production rate for $\Delta\left(\mathrm{CO}_{2 \mathrm{~T}}\right)_{\mathrm{b}}<0 \Leftrightarrow$ $\Delta\left(\mathrm{O}_{2}\right)_{\mathrm{b}}>0$; net mineralization rate for $\Delta\left(\mathrm{CO}_{2 \mathrm{~T}}\right)_{\mathrm{b}}>$ $0 \Leftrightarrow \Delta\left(\mathrm{O}_{2}\right)_{\mathrm{b}}<0$; and net remineralization reaction rate of the organic matter in the orientation of the vector $1-4$ (Fig. 1) were calculated.

$$
\begin{aligned}
& I=0.5 \times \sum_{i} Z_{i}^{2}[i] \quad(\text { eq. } 2) \\
& \log _{i}=-A \times Z_{i}^{2} \times\left[\left(\frac{I^{1 / 2}}{1+I^{1 / 2}}\right)-0.3 I\right] \\
& \Delta\left(C O_{2 T}\right)_{a}=0.5 \times\left(F C O_{2 T}\left(t_{0}\right)+F C O_{2 T}\left(t_{7}\right)\right) \\
& \Delta\left(C O_{2 T}\right)_{b}=\Delta\left(C O_{2 T}\right)-\Delta\left(C O_{2 T}\right)_{a} \\
& C_{e q}=C+\frac{M n}{6}+\frac{(C r+M o+V)}{5}+\frac{(N i+C u)}{15} \\
& \sum \Delta M(t)=[C(t)-C c(t-\Delta t)] \times V^{\prime}
\end{aligned}
$$

Where: [eq.2] I= is the activity coefficient of the ionic functions; $\mathrm{i}=$ major ionic species with corresponding electrical charges (Z); [eq.3] $f=$ ionic strength for $A=0.5[19,20]$; [eq.4] $\left(\mathrm{CO}_{2 \mathrm{~T}}\right)_{\mathrm{a}}=$ exchange liquid flux by diffusion at the watersediment interface in the interval $t$, and $\mathrm{FCO}_{2 \mathrm{~T}}$ in $t_{0}$ and $t_{7}$ represent the flux of $\mathrm{CO}_{2}$ in each moment $t$; [eq.5] $\left(\mathrm{CO}_{2 \mathrm{~T}}\right)_{\mathrm{b}}=$ net production or mineralization rate of $\mathrm{CO}_{2 \mathrm{~T}}$; [eq.6] $\mathrm{C}_{\mathrm{eq}}=$ represents the equivalent carbon with the element contents in \%; [eq.7] $\mathrm{C}(\mathrm{t})=$ solute concentration at time $\mathrm{t} ; \mathrm{Cc}=$ concentration of solute corrected in the previous sample as a function of time variation $(t-\Delta t)$; and $\mathrm{V}=$ volume of water overlying the core [18].

\section{RESULTS AND DISCUSSION}

\subsection{Sedimentary Characterization}

Table 1 presents some relevant characteristics of the sediment and pore water determined at the ACS. The granulometric analysis revealed the presence of mud sediments with high percentage of fine silt and clay in the coastal zone, with variation of $80.6-90.6 \%$ (mean $84.8 \pm 3.6 \%$ ). In the continental shelf area, not making a distinction between the influence of the river and marine currents, the values had high variation, from 5.8 to $81.4 \%$ (mean $53.6 \pm 29.1 \%$ ). Isolating the areas by influence of the currents, we have that the ACS inner shelf (sites 3 and 5) had concentrations of fine sediments between 70.7 $81.4 \%$ (average $76.0 \pm 5.3 \%$ ); and on the outer shelf (sites 1 and 2) from 5.8 to $56.1 \%$ (mean $31.2 \pm 25.5 \%)$. The coastal zone and the inner shelf presented enrichment of the bottom sediments with fine organic material originating from Amazon River sedimentary load. A similar pattern of change in particle size was observed by Gibbs [13], Garrels and Thompson [21], along the Amazon Shelf between 10 and 50 meter isobars above the North Cape (State of Amapá). According to the authors, the transition in the 
sedimentary pattern extended from the interior delta of the Amazon River towards the inner shelf with extensively reworked by intense tidal currents and waves. The bathymetry suggests a behavior in a little negative exponential curve. In other words, the increase in the depth of the coastal zone towards the ocean floor was slightly mild, with two very evident areas of reduction in the inclination of the curve: first one at 40 meters and the second one near 80 meters deep (Fig. $2 \mathrm{~A})$. The trend of accumulation of fine sediments in the fluvial-marine environment followed a distribution pattern, which can be explained by a variation of the Gaussian curve. The sedimentation - deposition and physicalreworking patterns indicated an area of maximum thickness of the thin sediment layer with approximately $62 \mathrm{~cm}$ high and $49 \mathrm{~km}$ away from the coastal zone (Fig. 2A). Similar patterns were observed by $[11,12]$. Aller et al. [12] observed a layer of fine sediment between 50 and $60 \mathrm{~cm}$ thick accumulated about $65 \mathrm{~km}$ from the coastline, above the North Cape between $1.5^{\circ}$ and $3.5^{\circ}$ north latitude, which the authors identified as a result of physical reworking of sediments from a circulation pattern influenced by NBC. According to the authors, vertical sediment-water zonation in particle mobility and concentration are therefore typically present at the region, with the relative zonal thicknesses determined seasonally by the relative dominance of physical processes and sediment supply at each site.
The organic matter (OM) and organic carbon (OC) contents in the study area varied, respectively: in ACS (sites 1, 2, 3 and 5) OM= $0.6-2.8 \%$ (mean $1.3 \pm 0.4 \%$ ) and $\mathrm{OC}=0.3-$ $1.8 \%$ (mean $0.8 \pm 0.3 \%$ ); only on the outside of the shelf, under the influence of marine currents, $\mathrm{OM}=0.6-2.8 \%$ (mean $1.5 \pm 0.5 \%$ ) and $\mathrm{OC}=0.3$ $-1.8 \%$ (mean $0.8 \pm 0.3 \%$ ); in the inner shelf, $\mathrm{OM}=$ $1.0-1.6 \%$ (mean $1.2 \pm 0.2 \%$ ) and $\mathrm{OC}=0.6-$ $0.9 \%$ (mean $0.7 \pm 0.1 \%$ ). As expected, the coastal zone presented the highest individual $\mathrm{OM}$ and $\mathrm{OC}$ contents in the sediments, varying between $\mathrm{OM}=2.2-4.9 \%$ (mean $3.3 \pm 0.7 \%$ ) and $\mathrm{OC}=0.5$ $-2.7 \%$ (mean $1.5 \pm 0.7 \%$ ). Most OM in water and sediment occurs as OC that has functional groups that form stable complexes with trace metals, due to its capacity of cations adsorption. Thus the presence of OC tends to increase the dissolved fraction of metals [22]. The decomposition of $\mathrm{OM}$ can affect both hydrodynamic processes and geochemical redox cycles, providing driving forces for metal mobilization [23]. The mobilization and distribution of trace metals in water-sediment systems are dependent on physical-chemical, especially $\mathrm{pH}$ and redox changes (DO levels), and microbiological mechanisms, mediated by the species transformation [24,25], as is observed in the diagenetic processes. The physical-chemical mechanisms involved include metal speciation, adsorption, precipitation, coprecipitation and diffusion $[22,26]$. The capacity of sediments to adsorb and retain trace metals is
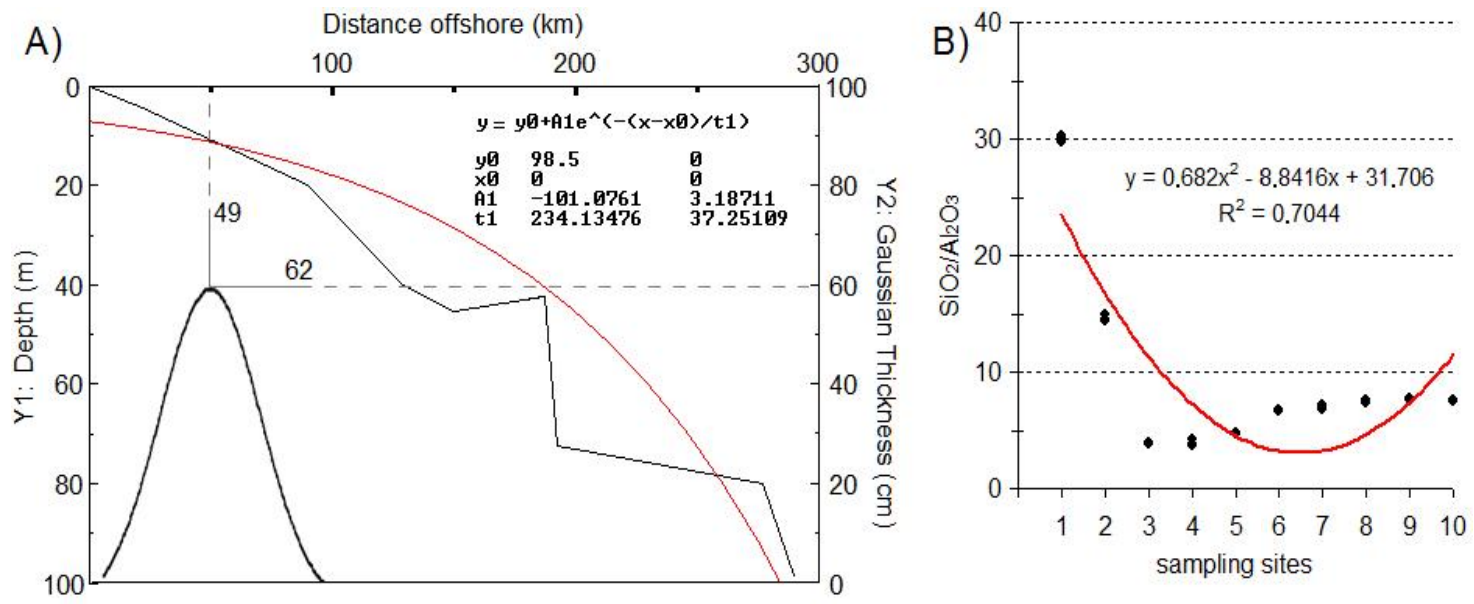

Fig. 2. A) Graphic representation of the oceanic relief (bathymetric profile) with exponential fitting curve (red line) and respective differential equations, behavior of sedimentation deposition processes and physical-reworking patterns in the coastal zone and ACS; B) Distribution pattern of the $\mathrm{SiO}_{2} / \mathrm{Al}_{2} \mathrm{O}_{3}$ ratio in the coastal zone and continental shelf with respective parabolic fitting curve (red line of tendency) and equation 
Table 1. Some characteristics of the sediment and pore water determined at the ACS (minimum and maximum values by zone)

\begin{tabular}{|c|c|c|c|c|c|c|c|c|c|c|}
\hline & \multicolumn{4}{|c|}{ Sediment } & \multicolumn{6}{|c|}{ Pore water } \\
\hline & Water depth & Porosity & Sand & Silt+Clay & OC & Salinity & $\mathrm{pH}$ & $\mathrm{O}_{2}$ & $\mathrm{Fe}^{2+}$ & $\mathrm{Fe}^{3+}$ \\
\hline & $\bar{m}$ & $\mathrm{ml} / \mathrm{cm}^{3}$ & $\%$ & $\%$ & $\%$ & $(\mathrm{dS} / \mathrm{m})$ & & $\%$ & $\mathrm{mmol} / \mathrm{L}$ & $\mathrm{mmol} / \mathrm{L}$ \\
\hline \multirow{2}{*}{$\mathrm{ACS}^{*}$} & 40.0 & 0.25 & 18.6 & 5.8 & 0.32 & 35.5 & 7.99 & 22.79 & 0.02 & 0.04 \\
\hline & 98.5 & 0.40 & 94.2 & 81.4 & 1.78 & 38.4 & 8.21 & 57.60 & 0.03 & 0.05 \\
\hline \multirow{2}{*}{$C Z$} & 4.5 & 0.66 & 9.4 & 80.6 & 0.46 & 4.9 & 6.51 & 5.64 & 0.04 & 0.04 \\
\hline & 8.3 & 0.70 & 19.4 & 90.6 & 2.70 & 6.0 & 7.84 & 18.63 & 0.06 & 0.07 \\
\hline \multirow{2}{*}{ Inner } & 40.0 & 0.25 & 18.6 & 70.7 & 0.55 & 35.5 & 7.99 & 22.79 & 0.03 & 0.04 \\
\hline & 42.2 & 0.40 & 29.3 & 81.4 & 0.88 & 37.7 & 8.21 & 38.54 & 0.03 & 0.05 \\
\hline \multirow{2}{*}{ Outer } & 72.4 & 0.28 & 43.9 & 5.8 & 0.32 & 36.3 & 8.03 & 39.37 & 0.02 & 0.04 \\
\hline & 98.5 & 0.34 & 94.2 & 56.1 & 1.78 & 38.4 & 8.18 & 57.60 & 0.02 & 0.05 \\
\hline
\end{tabular}
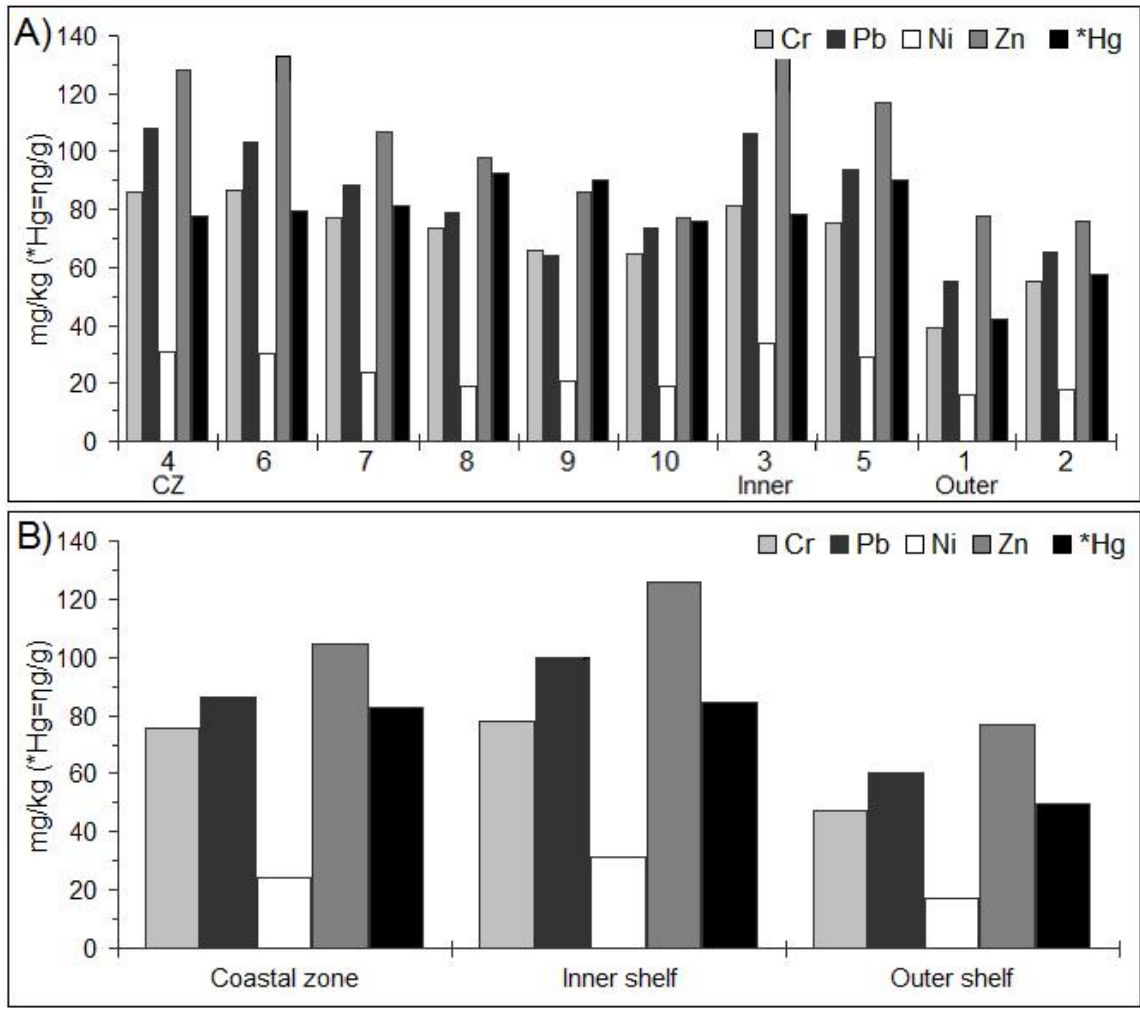

Fig. 3. AB. medium concentration and trend of the trace metals in the $C Z$ and $A C S$, blue Amazon - Brazil

also dependent of other variables as the availability of $\mathrm{Fe}$ and $\mathrm{Mn}$, presence of carbonate and the clay minerals levels.

The accumulation of $\mathrm{OM}$ associated to fine fractions of clay increased the porosity of the sediments at the coastal zone $(0.66-0.7$ $\mathrm{ml} / \mathrm{cm}^{3}$ ), while in the outer shelf, owed mainly the uniformity of the grain size, the sandy sediments presented the smallest porosities values $(0.28-$ $0.34 \mathrm{ml} / \mathrm{cm}^{3}$, Table 1). The porosity is defined as the amount of water that a rock or sediment can store. For this reason, porosity also can interfere in the metallic ions levels and consequent mobilization and distribution in the pore water, allowing the accumulation (stock) of metals in the sediment compartment. 
Table 2. Pearson's correlations: Bold correlations are significant at $p<0.050$ and $n=110$ (values with 3 decimals. $\pm x y z$ )

\begin{tabular}{|c|c|c|c|c|c|c|c|c|c|c|c|c|c|c|c|}
\hline & Depth & OM & OC & IC & Sand & Silt & Clay & Si/Al & DO & $\mathrm{O}_{2} \% \mathrm{pH}$ & Sal & $\mathrm{Cr}$ & $\mathrm{Pb}$ & $\mathbf{N i}$ & $\mathrm{Zn}$ \\
\hline \multicolumn{16}{|c|}{ Depth 1.0} \\
\hline $\mathrm{OM}$ & -.703 & 1.0 & & & & & & & & & & & & & \\
\hline$O C$ & -.476 & .875 & 1.0 & & & & & & & & & & & & \\
\hline IC & .424 & -.718 & -.860 & 1.0 & & & & & & & & & & & \\
\hline Sand & .915 & -.715 & -.556 & .343 & 1.0 & & & & & & & & & & \\
\hline Silt & -.737 & .383 & .205 & -.202 & -.912 & 1.0 & & & & & & & & & \\
\hline Clay & -.944 & .776 & .537 & -.386 & -.958 & .760 & 1.0 & & & & & & & & \\
\hline $\mathrm{Si} / \mathrm{Al}^{1}$ & .803 & -.780 & -.692 & .085 & .937 & -.863 & -.892 & 1.0 & & & & & & & \\
\hline DO & -.464 & -.719 & -.677 & -.704 & -.145 & .082 & .233 & .105 & 1.0 & & & & & & \\
\hline $\mathrm{O}_{2} \%$ & -.299 & -.644 & -.525 & -.312 & .011 & -.125 & .081 & .249 & .948 & 1.0 & & & & & \\
\hline $\mathrm{pH}$ & .686 & -.713 & -.754 & .711 & .565 & -.429 & -.599 & .293 & -.531 & -.4191 .0 & & & & & \\
\hline $\mathrm{Sal}^{2}$ & .882 & -.830 & -.583 & .522 & .849 & -.466 & -.709 & .444 & -.801 & -.6620 .755 & 1.0 & & & & \\
\hline $\mathrm{Cr}$ & -.565 & .632 & .601 & -.226 & -.715 & .738 & .729 & -.840 & -.408 & -.307.070 & -.476 & 1.0 & & & \\
\hline $\mathrm{Pb}$ & -.258 & .617 & .540 & -.507 & -.425 & .490 & .437 & -.650 & -.592 & -.444 .418 & -.229 & .909 & 1.0 & & \\
\hline $\mathrm{Ni}$ & -.034 & .783 & .666 & -.612 & -.674 & .529 & .340 & -.522 & -.758 & -.473 .573 & -.474 & .794 & .926 & 1.0 & \\
\hline $\mathrm{Zn}$ & -.041 & .732 & .663 & -.611 & -.231 & .634 & .337 & -.470 & -.650 & -.564 .586 & -.409 & .821 & .945 & .961 & 1.0 \\
\hline $\mathrm{Hg}$ & -.515 & .516 & .497 & .013 & -.691 & .809 & .624 & -.714 & -.324 & - -251.070 & -.489 & .789 & .705 & .627 & .573 \\
\hline
\end{tabular}

Table 3. Weight factor $\left(F_{\mathrm{w}}\right)$ of the parameters analyzed in the distribution and mobility of trace elements

\begin{tabular}{|c|c|c|c|c|c|c|c|c|c|c|c|c|c|c|c|c|}
\hline depth & OM & $O C$ & IC & sand & silt & clay & Si/Al & DO & $\mathrm{O}_{2} \%$ & $\mathrm{pH}$ & sal & $\mathrm{Cr}$ & $\mathrm{Pb}$ & $\mathbf{N i}$ & $\mathrm{Zn}$ & $\mathrm{Hg}$ \\
\hline-0.9 & 0.9 & 0.8 & -0.6 & -1.0 & 0.6 & 0.8 & -1.0 & -0.8 & -0.6 & 0.1 & -0.3 & 0.8 & 0.6 & 0.8 & 0.7 & 0.6 \\
\hline
\end{tabular}

Table 4. Estimates of net production and net mineralization of organic matter from the incubation test $(t=96 h)$ for sites 1 (outer shelf) and 4 (coastal zone)

\begin{tabular}{|c|c|c|c|c|c|c|c|c|}
\hline \multirow[t]{2}{*}{$\overline{\text { Site }}$} & \multirow[t]{2}{*}{$\begin{array}{l}\text { Depth } \\
(\mathrm{m})\end{array}$} & \multicolumn{2}{|c|}{$\begin{array}{l}{\left[\mathrm{CO}_{2 \mathrm{~T}}\right]} \\
(\mathrm{mmol} / \mathrm{L})\end{array}$} & \multirow[t]{2}{*}{$\begin{array}{l}\Delta \mathrm{CO}_{2 \mathrm{~T}} \\
(\mathrm{mmol} / \mathrm{L})\end{array}$} & \multirow[t]{2}{*}{$\begin{array}{l}\Delta \mathrm{l}^{*} \\
\text { (meq/L) }\end{array}$} & \multirow[t]{2}{*}{$\begin{array}{l}F_{i}^{* *} \\
(\log ) \\
\end{array}$} & \multirow[t]{2}{*}{$\begin{array}{l}\Delta \mathrm{NH}_{4}{ }^{+} \\
(\mu \mathrm{mol} / \mathrm{L})\end{array}$} & \multirow[t]{2}{*}{$\mathrm{Fe}^{2+} / \mathrm{Fe}^{3+}$} \\
\hline & & $\mathrm{t}_{0}$ & $\mathrm{t}_{96}$ & & & & & \\
\hline 1 & 0.0 & 3.30 & 4.10 & 1.44 & 1.81 & -1.50 & -9 & 0.35 \\
\hline 1 & 0.5 & 3.50 & 4.80 & & & & & 0.54 \\
\hline 4 & 0.0 & 3.60 & 6.60 & 4.94 & 3.26 & -0.48 & 53 & 0.65 \\
\hline 4 & 0.5 & 3.80 & 8.70 & & & & & 1.45 \\
\hline
\end{tabular}

The $\mathrm{SiO}_{2} / \mathrm{Al}_{2} \mathrm{O}_{3}$ ratio followed the same trend presented for grain size, with a total variation in the study area from 3.7 (site 4) to 30.3 (site 1), and averages by zoning of $13.3 \pm 10.8$ in ACS; $4.3 \pm 0.5$ in the inner shelf; $22.3 \pm 8.1$ in outer shelf; and $6.7 \pm 1.3$ in the coastal zone. These results confirm the proportion of silicates as a function of sediment transported, with a strong distinction between the low $\mathrm{SiO}_{2} / \mathrm{Al}_{2} \mathrm{O}_{3}$ ratio in the sediments deposited by the fluvial currents (Amazonas and Pará rivers) and the high ratio in the sandy sediments reworked by the marines currents (Fig. 2B). It is correct to say that the sediment characteristics found at each sampling site were influenced not only by the currents, but also by the depth of the bed. The shallower areas presented higher sedimentary deposition load, with accumulation of fine sediments. On the other hand, the deeper areas presented greater resuspension and swirling capacity, preventing the deposition of fine sediments.

\subsection{Distribution of Trace Elements}

The trace metal contents varied between $\mathrm{Cr} 36.5$

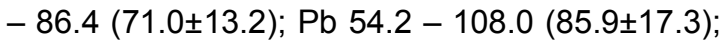

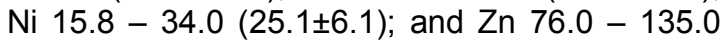
$(108.0 \pm 21.7) \mathrm{mg} / \mathrm{kg}$ and $\mathrm{Hg} 66.0$ - 113.2 

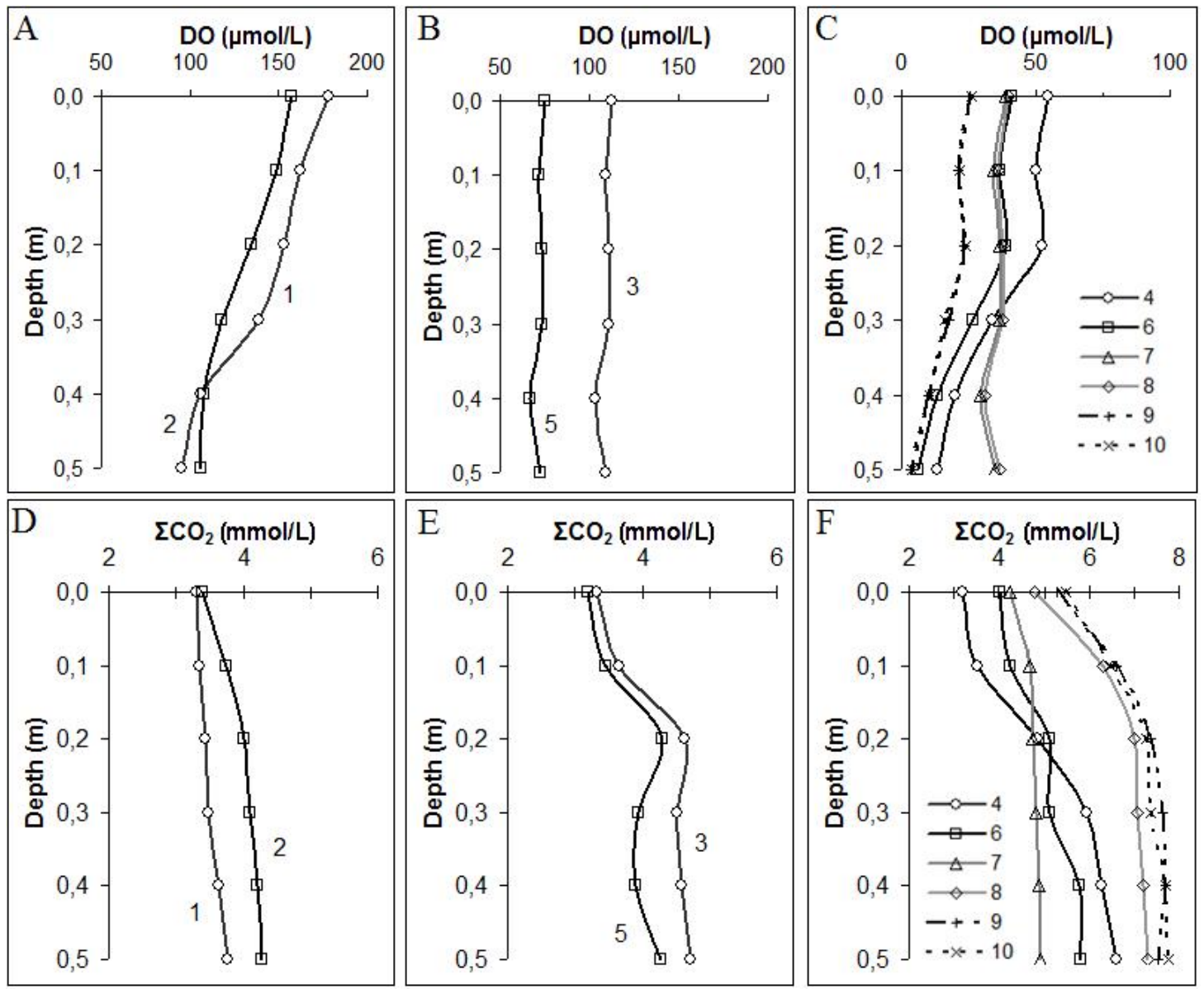

Fig. 4. Vertical profile of $\mathrm{DO}(\mu \mathrm{mol} / \mathrm{L})$ and $\Sigma \mathrm{CO}_{2}(\mathrm{mmol} / \mathrm{L})$ according to the zoning process: $\left.A\right)$ and $D$ ) outer shelf; B) and E) inner shelf; $C$ ) and F) coastal zone

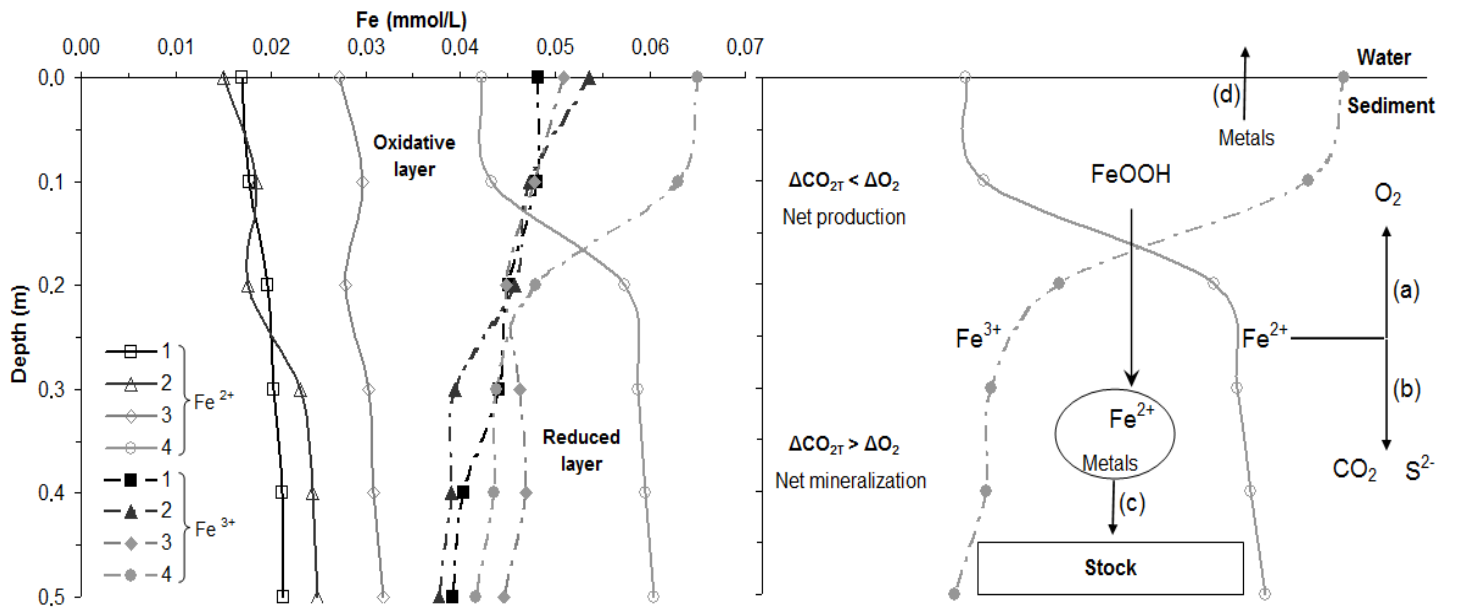

Fig. 5. Vertical profile of the $\mathrm{Fe}^{2+}$ and $\mathrm{Fe}^{3+}$ fractions in the pore water from sediments located in the vector 1-4 of the ACS, and indication of the possible transport routes of the associated trace elements

Legend: a) decomplexing; b) co-precipitation; c) fixation; d) mobilization 
(77.8 \pm 11.4$) \quad \mathrm{ng} / \mathrm{g} \quad$ (Fig. 3A). The following behaviors were observed: 1 ) tendency to greater fraction of fine sediments in the inner shelf by direct influence of the high sedimentary load of the Amazon River mouth; 2) absence of OM in the sediments of the outer shelf by the continuous flow of the ocean currents from southeast to northwest; 3) a strong seasonality in the volume of sediment transported due to rainfall. The concentration of trace metals in the sediments followed the same convergence observed for the sediment flow, establishing a pattern with higher levels of trace metals in the $\mathrm{CZ}$ and inner shelf, and lower levels in the outer shelf (Fig. 3B).

An important aspect in the flow of metals is the high capacity of metallic adsorption by the clay minerals in the sedimentary transport regime (discussed in the item 4.1). The high cation exchange capacity observed in the clay and OM particles, associated to the slightly acidic $\mathrm{pH}$ conditions in the fluvial-marine system, contributed to the storage of the trace metals especially in the inner shelf, as bivalent forms. This explains the positive correlation pattern calculated for OM, clay and trace elements. The Pearson correlation indexes calculated between $\mathrm{OM}$ and trace elements ranged from $0.516 \mathrm{Hg}$ to $0.783 \mathrm{Ni}$ (Table 2). There was also observed a significant correlation between $\mathrm{OM}$ and fine clay particles $(0.776)$. In relation to the adsorption and desorption processes of the particles, the increase of the silicate load in the sediments of the outer shelf reduced the OM and clay contents and, consequently, of trace elements available for mobilization. The bioavailability of a trace metal, and consequently its toxicity, both depend on the form in which the metal is found (degree of speciation). Factors such as $\mathrm{pH}$, Eh, alkalinity, degree of oxidation, suspended solids (OM and clay minerals), oxygen and temperature interfere with the mobility/precipitation ratio of trace metals. The $\mathrm{pH}$ has an important controlling role in the precipitation of the metallic elements through its ability to attack the minerals of rocks, soils and sediments [22], inducing the leaching or solubilization of the metals. During the leaching process, oxygen can be partially consumed to oxidize $\mathrm{OM}$ and reducing it to simpler inorganic fractions. Thus, the contribution of $\mathrm{O}_{2}$ transferred from the cooler ocean currents to the sedimentary layer, especially in the first half meter, interferes in the OM-metals and claymetals adsorption mechanism, a tendency observed in the negative correlation between the parameters. The depth of the sedimentary bed also showed a significant correlation, in this case with $\mathrm{OM}$, sedimentary fractions, $\mathrm{pH}$ and salinity (Table 2).

A normalization index was applied to the absolute values in order to establish the importance or 'weight factor' $\left(F_{w}\right)$ of each parameter under the distribution and mobility of trace elements in the studied area. The normalization to establish a 'weight factor' is a practice usual in the creation of indexes such as the Water Quality Index, first applied by Brown and McClelland [27] for the National Sanitation Foundation (US NSF). Equation 8 presents the applied normalization calculation. The numerical values in front of each parameter indicate their 'weight' of importance in the general tendency, and the signal (positive or negative) of each parameter indicates if the proportionality was direct or indirect in relation to the concentration of trace elements in the sediments. The results suggest that the mobility of $\mathrm{Cr}, \mathrm{Ni}$ and $\mathrm{Zn}$ is strongly related to the depth and location of sampling sites; sand, clay, OM and OC levels, and the DO concentration (Table 3).

$$
F w=\frac{A v r \times(S D)^{2}}{M a x^{2}-M i n^{2}}
$$

Where: $F_{w}=$ weight factor; Avr= average; $\mathrm{SD}=$ standard deviation; Max= maximum and Min=minimum .

\subsection{Diagenetic Processes}

The series of physical-chemical transformations of OM, occurring in the water and sediment compartments, including pore water, is known as diagenesis. It is an essential process for the cycling of nutrients, allowing the renewal of marine life. In the diagenesis, several redox reactions occur due to the decomposition of OM by bacterial activity (reactions of Froelich et al. [28], whose main regulating factor is the concentration of DO in the sedimentary layer, especially in pore water. In aquatic sediments it is usual to continuously produce organic compounds through decomposition, by aerobic and anaerobic pathways, as well as mineralization of $\mathrm{OM}$ from the breathing and fermentation processes. Add to this autochthonous organic load the volume of organic compounds carried by the streams, especially bottom streams, and deposited over an area, incorporating organic compounds into the processes mentioned above. 
The relationship between the production and consumption of organic material defines the metabolism of an ecosystem, in this case benthic or sedimentary. In the euphotic zone, the processes of production exceed the mineralization in the diurnal phase $\left[\Delta\left(\mathrm{CO}_{2 \mathrm{~T}}\right)_{\mathrm{b}}=\right.$ $\mathrm{n}]$, reversing the direction of the reaction at night $\left[\Delta\left(\mathrm{CO}_{2 \mathrm{~T}}\right)_{\mathrm{b}}=+\mathrm{n}\right]$. In addition to $\mathrm{O}_{2}$, physical and physical-chemical factors such as stream flow, sediment porosity, sedimentation rate, watersediment interface temperature, $\mathrm{pH}$, alkalinity, cation exchange capacity (CEC), trace element concentration, $\mathrm{OM}$, respiration rate and intensity of benthic biological activity determine the way diagenesis occurs, especially in the time of nutrient regeneration rate. By analyzing the sampling sites by zoning, it was possible to identify areas of low $\mathrm{O}_{2}$ content, with an increase in $\mathrm{CO}_{2 \mathrm{~T}}$ levels. These results suggest moments of reduction of $\mathrm{Fe}^{3+}$ and $\mathrm{Mn}^{4+}$ (equations 9 and 10) [28], especially in areas with high OM content and protected from currents such as site 4 below 0.2 meters (Fig. 1). Degradation of the organic matter by the reduction of $\mathrm{Mn}^{4+}$ (eq.9) is thermodynamically more favorable than the reduction of $\mathrm{Fe}^{3+}$ (eq.10). However, the iron reduction pathway is considered to be more important for the mobility and/or co-precipitation of trace elements in the coastal zone and inner shelf, because the total $\mathrm{Fe}$ concentration in the Amazonian continental waters is about 100 times higher than the concentration of manganese. The mean total $\mathrm{Fe}$ and $\mathrm{Mn}$ concentration determined in the Amazon River waters is $1.3-$ $3.4 \mathrm{mgFe} / \mathrm{L}$ and $0.009-0.08 \mathrm{mgMn} / \mathrm{L}$ (Darwich and Aprile, unpublished data). Sequence of oxidant species observed in the sedimentary layer [28]:

$$
\begin{aligned}
& \left(\mathrm{CH}_{2} \mathrm{O}\right)_{106}\left(\mathrm{NH}_{3}\right)_{16}\left(\mathrm{H}_{3} \mathrm{PO}_{4}\right)+236 \mathrm{MnO}_{2}+ \\
& 472 \mathrm{H}^{+} \underset{\rightarrow}{\rightarrow} 236 \mathrm{Mn}^{2+}+106 \mathrm{CO}_{2}+8 \mathrm{~N}_{2}+\mathrm{H}_{3} \mathrm{PO}_{4} \\
& +366 \mathrm{H}_{2} \mathrm{O}
\end{aligned}
$$

$\left(\mathrm{CH}_{2} \mathrm{O}\right)_{106}\left(\mathrm{NH}_{3}\right)_{16}\left(\mathrm{H}_{3} \mathrm{PO}_{4}\right)+212 \mathrm{Fe}(\mathrm{OH})_{3}+$ $636 \mathrm{H}^{+} \rightarrow 212 \mathrm{Fe}^{2+}+106 \mathrm{CO}_{2}+16 \mathrm{NH}_{3}+$ $\mathrm{H}_{3} \mathrm{PO}_{4}+636 \mathrm{H}_{2} \mathrm{O}$

Although in the coastal zone and inner shelf areas occurs large deposition of $\mathrm{OM}$, factors such as slightly alkaline $\mathrm{pH}$ and low interstitial $\mathrm{O}_{2}$ levels may be contributing to the reduction of mobility of trace elements. Considering that part of the DO content is being consumed by the OM oxidation, the process of deposition and reduction of the metallic mobility intensifies, ensuring that this sedimentary layer acts preferentially as a storage compartment (stock) of trace elements. Vertical profiles of the $\mathrm{O}_{2}$ and $\Sigma \mathrm{CO}_{2}$ contents in the pore water of the sedimentary layer of the sampled sites were elaborated (Fig. 4). In general, the sandy sedimentary layer had a greater flow of oxygenation than the mud layers of the coastal zone and inner shelf. DO contents in the $0.0-$ $0.5 \mathrm{~m}$ ranged from $95.6-178.1 \mu \mathrm{mol} / \mathrm{L}$ on the outer shelf; of $66.5-112.5 \mu \mathrm{mol} / \mathrm{L}$ on the inner shelf; and $3.1-54.4 \mu \mathrm{mol} / \mathrm{L}$ in the coastal zone (Fig. 4). The bottom currents in the outer shelf, cooler and oxygenated, they interfered in the sedimentary $\mathrm{O}_{2}$ flux, facilitated by the porosity of the sandy sediments. It can be pointed out that the diffuse oxygen flux in the sediments was directed by the consumption in the oxidation process. The oxidation of organic matter in fluvial-marines sediments is considered the most important form of respiration in fluvial-marine sediments [29]. Besides, another factor may be contributing to diffuse oxygen flow, in this case a biological action involving benthic respiration, especially in coastal sediments. Studies on oxygen flow and oxireduction of nitrogenous and sulfated forms $\left(\mathrm{NO}_{3}\right.$ and $\left.\mathrm{SO}_{4}\right)$ performed in the same region demonstrated the importance of the benthic respiration in diagenetic processes [2931]. In general, aerobic respiration takes place in the oxic surface layer and is followed by nitrate and sulfate reductions. However, in coastal sediments the oxic zone often is only a few millimeters thick, as suggest the studies of Aller et al. [12] and Froelich et al. [28], and exactly as observed in the sediments of the coastal zone and inner shelf of the ACS, where the anaerobic respiration becomes dominant. Besides, much of the oxygen uptake is used to reoxidate the products of anaerobic respiration as $\mathrm{H}_{2} \mathrm{~S}, \mathrm{NH}_{4}{ }^{+}$and $\mathrm{CH}_{4}$ at the oxic/anoxic interface of the sediment [32].

The mineralization of the anaerobic organic matter involves several oxidation processes, consuming nitrates, $\mathrm{Fe}$ and $\mathrm{Mn}$ oxides, sulfates and carbonic acid to form $\mathrm{CO}_{2}$ and fermentation, in this case with formation of $\mathrm{CH}_{4}$ (methanogenesis). Due to its greater stability in relation to $\mathrm{H}_{2} \mathrm{~S}$ and $\mathrm{SO}_{4}{ }^{2-}$, the $\mathrm{CO}_{2}$ becomes an important indicator of diagenetic processes. In general, is considerate for analysis the sum of all dissolved carbonate forms, which are defined as total inorganic carbon or $\mathrm{CO}_{2 \mathrm{~T}}$. The concentration oscillation of both free $\mathrm{CO}_{2}$ and $\mathrm{CO}_{2 \mathrm{~T}}$ depends directly on the production and consumption in the processes already mentioned, $\mathrm{pH}$, alkalinity of the carbonates and ionic composition of the water. The carbonate content, which interferes 
with $\mathrm{pH}$ and alkalinity, has as main source in the marine environments the contribution carried by the waterways and biogenic production, whose main raw materials are plankton and mollusks. In relation to carbonate content, in the Amazonian plain the main source of carbonate is predominantly $\mathrm{HCO}_{3}^{-}$[33]. The biogenic production of carbonate in shallow waters and its dissolution in deep waters causes a dynamic equilibrium system, affected by ocean currents, and that controls, among other factors, the concentration of total inorganic carbon in the system. The $\mathrm{CO}_{2 \mathrm{~T}}$ contents presented some variability as a function of zonation, ranging from $3.3-4.3 \mathrm{mmol} / \mathrm{L}$ in the outer shelf; of $3.3-4.7$ $\mathrm{mmol} / \mathrm{L}$ on the inner shelf; and $3.2-7.8 \mathrm{mmol} / \mathrm{L}$ in coastal zone sediments (Fig. 4). The higher $\mathrm{CO}_{2}$ levels in the sediments are associated with decomposition processes and complete oxidation of organic matter and mineralization partially anaerobic of the sedimentary particles. All the sampling sites showed a considerable capacity for a rapid change in pore water constituents associated with the remineralization processes, suggesting the presence of abundant organic compounds, especially in the inner shelf that, as mentioned above, act primarily as a storage compartment of thin sediments, depending on their morphology and flow direction. At some sampling sites, the exponential decay of $\mathrm{O}_{2}$ occurred simultaneously to $\mathrm{CO}_{2}$ production, especially at depths of $0.0-0.2$ meters in the sedimentary layer. This behavior reflects the nature of particle deposition and reworking of particles. It should be remembered that the samplings and measurements were carried out during the months of the lowest flow in the Amazon and Pará rivers and at the ACS. Thus, it is plausible to believe that seasonality can alter the flow pattern of oxygen as well as $\mathrm{CO}_{2}$ during the hydrological year, especially during the periods of higher flow of the Amazon River, when the sediment load transported can reach double volume, as has been suggested by Meade et al. [10] and Gibbs [13].

\subsection{Sedimentary Incubation}

Incubation tests can be classified into open and closed systems. In the open system the loss of $\mathrm{CO}_{2}$ by diffusion is allowed, which does not return to the system. However, the closed system is often questioned by 'imprisoning' the gases, preventing the changes at the watersediment interface. The fact is that both tests have positive and negative points, and it must be assumed that there is an imprecision in the results. The great trump of incubation tests, however, is the ability to quantitatively estimate the processes involved. It is based on this perspective that a closed test was applied to estimate the net productivity and mineralization content of OM in the coastal zone and ACS.

The variation of the $\mathrm{CO}_{2 \mathrm{~T}}$ and $\mathrm{O}_{2}$ in the waters $\left(\Delta \mathrm{CO}_{2 \mathrm{~T}}(\mathrm{t})\right.$ and $\left.\Delta \mathrm{O}_{2}(\mathrm{t})\right)$, including the pore waters, is controlled not only by the biological processes but also by the diffusion rate of the gases in the interface zone $\left(\Delta\left(\mathrm{CO}_{2 \mathrm{~T}}\right)_{\mathrm{a}}\right.$ and $\left.\Delta\left(\mathrm{O}_{2}\right)_{\mathrm{a}}\right)$, and the facilitation or not of the gas flow as a function of the degree of sedimentary porosity. Thus, the study of the diagenetic processes involving the production and mineralization from the $\mathrm{CO}_{2}$ and $\mathrm{O}_{2}$ variations in the water should be understood as an estimate, since there are several factors controlling the concentration and flow of these gases in the sediments, including hydrodynamics and seasonality. The closed incubation technique attempts to minimize the problem of gas exchange. Despite this, incubation reduces the flow of biogenic elements. The system's buffering capacity is of great relevance to the results, since any change in $\mathrm{pH}$ and alkalinity, especially alkalinity of carbonate $\left(\mathrm{Alc}_{\mathrm{c}}\right)$, interferes with the concentrations of $\mathrm{H}_{2} \mathrm{CO}_{3}, \mathrm{HCO}_{3}{ }^{-}$and $\mathrm{CO}_{3}{ }^{2-}$, and consequently with $\mathrm{CO}_{2 \mathrm{~T}}$ levels. It is tried to minimize this variation, considering that the chemical reactions and the diffusions present kinetics of the same order. Thus, when $\mathrm{CO}_{2}$ adsorption occurs, a part of the $\mathrm{CO}_{2}$ that enters the system is transformed into carbonates, and when the $\mathrm{CO}_{2}$ desorption occurs, a fraction of carbonates from the system is converted into $\mathrm{CO}_{2}$. Incubation tests confirmed that the range of $0.0-0.2 \mathrm{~m}$ is essentially the most active from the point of view of sediment reworking by the flow and inflow of the dissolved gases. As expected, $\mathrm{CO}_{2 \mathrm{~T}}$ rates increased rapidly during the incubation period. Increasing the concentration of inorganic carbon forms may mean an increase in aerobic decomposition rates (complete decomposition), due to the increase in the supply of reactive organic compounds. Generally, the saturation of mineral carbonates and other forms of inorganic carbon are quite high in the sediments from ACS, as were observed by Aller et al. [2], Aller et al. [12].

In the comparison of the results between the incubation of sediments from site 1 , sandy and 
under strong influence by marine currents, to site 4, mud and located in protected area with marked sedimentation, the amplitude of variation for the incubation period $\left(t_{0} \rightarrow t_{96}\right)$ was much higher at site 4 . The $\Delta \mathrm{CO}_{2 \mathrm{~T}}$ determined were respectively; site $1=1.44 \mathrm{mmol} / \mathrm{L}$ and site $4=$ $4.94 \mathrm{mmol} / \mathrm{L}$ (Table 4), suggesting that the net mineralization exceeded the net production of organic matter to $\left[\Delta\left(\mathrm{CO}_{2 \mathrm{~T}}\right)_{\mathrm{b}}>0\right.$ for $\left.\Delta\left(\mathrm{O}_{2}\right)_{\mathrm{b}}<0\right]$. The coefficient of activity (I) also showed a greater amplitude of variation in site $4(\Delta \mathrm{l}=3.26$ $\mathrm{meq} / \mathrm{L})$ compared to site $1(\Delta \mathrm{l}=1.81 \mathrm{meq} / \mathrm{L})$. The activity coefficient is a function not only of the chemical species present, but also of the ionic interactions in pore water. In silica sediments, the ionic interactions are weak and easily disrupted by the current underflow, which eventually penetrates the sediments due to their high porosity. Already in silt-clayey and clay-silty sediments, the low porosity $\left(<0.7 \mathrm{ml} / \mathrm{cm}^{3}\right)$ reduces the mobility of the mineral elements, accentuating the ionic interactions, which present strong connections, especially cationic, with the negative external surface of the particles of clay and organic matter. The ionic forces $\left(F_{i}\right)$, determined as a function of their logarithms, followed the same trends, being greater in the mud sediments. These behaviors are confirmed in the CEC analysis. Another important aspect is the variation rate in the productivity of $\mathrm{NH}_{4}^{+}$ions (Table 4), which showed influx in sandy sediments (site $1=-9$ $\mu \mathrm{mol} / \mathrm{L}$ ), and high efflux for mud sediments (site $4=53 \mu \mathrm{mol} / \mathrm{L})$.

Extrapolating the results of the incubation test to the study area, it is possible to establish some hypotheses: 1) the flow of marine currents at site 1 may be allowing the aerobic oxidation in these sedimentary layers, with the nitrification route more pronounced than the ammonification rote; 2 ) in the region of the coastal zone and inner shelf the routes of oxidation and reduction may be alternating according to the physical, physicalchemical and seasonal factors; 3 ) in the coastal zone and inner shelf the net mineralization rate has exceeded the net production rate of organic matter, since the calculations show $\Delta\left(\mathrm{CO}_{2 \mathrm{~T}}\right)>0$ for $\Delta\left(\mathrm{O}_{2}\right)<0$ (Table 4 ) for the vector from site 1 to site 4 (Fig. 1). It should be considered, however, that the rate of sedimentation or continuous contribution of sediments from the Amazon River to the inner shelf is immense, as already discussed.

Daily fluctuations in the rate of $\mathrm{NH}_{4}^{+}$production at the same site, with changes in the axis of orientation of influx - efflux (nitrification/ ammonification) are not uncommon, having been observed even in incubation tests [29,30]. In specific case of the sediments located in the axis of orientation of the vector shown in Fig. 1, it is believed that the great difference in porosity and OM contents of the sediments, associated to the depth of the layer, were the predominant factors in the change of the orientation axis of inflowefflux. This was confirmed by determination of iron fractions. Most of the time $\mathrm{Fe}^{2+} / \mathrm{Fe}^{3+}$ ratio was $<1.0$ throughout the sedimentary profile (Fig. 5 ), suggesting a mild to moderate oxidation pattern in the first $0.4 \mathrm{~m}$, especially for outer shelf sites (sampling sites 1 and 2). A sensitive reduction in the degree of oxidation of the ferric ions was observed in sites 2 and 3 from $0.4 \mathrm{~m}$. However, site 4 (Silt + Clay> 80\%) presented higher iron ratio, with $\mathrm{Fe}^{2+} / \mathrm{Fe}^{3+}>1.0$, indicating a predominance of the maintenance of the reduced form of iron $\left(\mathrm{Fe}^{2+}\right)$, which by electric affinity remains in the sedimentary layer adsorbed the particles of clay minerals and organic compounds not totally mineralized. Metal profiles sensitive to oxidation variation, such as $\mathrm{Fe}$ and $\mathrm{Mn}$, may indicate redox potential changes within the sedimentary layers, being influenced by the concentration of DO in the pore water. The pore water column can define alternate zones of oxidation and reduction of chemical species as a function of depth, according to sedimentation rates, oxygen demand, nutrients and microbiological processes [34]. The processes of dissolution and precipitation of minerals can affect the nutrient concentration $(\mathrm{C}, \mathrm{N}$ and $\mathrm{P})$ and trace elements in the sediments [8], because these chemical species may be adsorbed by the surface of minerals as iron oxides and hydroxides. The behavior of the trace elements in the bottom sediments is strongly associated with organic matter rates; $\mathrm{pH}$ (increase of the $\mathrm{pH}$ implies increase of the metallic adsorption); $\mathrm{O}_{2}$ content; redox potential; seasonality (flow of alternating currents); and diagenetic processes, which occur in the fluvial-marine system. In this case, three routes of adsorption of trace elements to the iron in the sediments and pore water can be established, taking into account the depth and oxygen content: 1) adsorption in $\mathrm{Fe}^{3+}$ oxides and hydroxides, especially at the watersediment interface and with increased metal mobility; 2) dissolution of $\mathrm{Fe}^{2+}$ oxides and hydroxides in the layers of less interference of $\mathrm{O}_{2}$, in this case the trace elements may follow the oxidative route towards the interface, or to stay associated with reduced forms $\left(\mathrm{S}^{2-}\right)$ and follow the co-precipitation way; and 3 ) fixation on 
the mineral surface or precipitation in the autigenic mineral phase, in or near the anoxic environment (Fig. 5). Reactive trace elements such as $\mathrm{Cu}, \mathrm{Ni}$ and $\mathrm{Zn}$ may have their concentrations controlled by co-precipitation with Fe sulfides, which would result in the reduction of the metallic mobility of these elements. Comparing the trace element contents with the vertical distribution profile of the iron fractions, it was possible to evidence an increase in trace element concentrations in $\mathrm{Fe}$ reduction zones, indicating processes of desorption of iron oxides and hydroxides, and mineralization of organic matter.

\section{CONCLUSION}

There is a strong zonation in the sedimentary transport and deposition processes, influenced by the granulometry and texture of the sediments, and the fluvial-marine currents, which alternate in direction seasonality. Thus, it was possible to identify that the sediments of the coastal zone and inner shelf are predominantly silt-clayey and clay-silty as opposed to sandy and sand-silt sediments of the outer shelf. The trace elements presented a distribution and concentration pattern equivalent to that of the sedimentary distribution pattern, with higher metallic contents in the deposits of clay and organic matter of the coastal zone and inner shelf. The determination of a weight factor $\left(F_{w}\right)$ calculated to estimate the degree of importance of each physical and physical-chemical parameter in the distribution and mobility of trace elements showed that these elements were strongly related to the depth and location of sampling sites, sand, clay, OM and OC levels, and $\mathrm{DO}$ concentration, especially to $\mathrm{Cr}, \mathrm{Ni}$ and $\mathrm{Zn}$ metals. The vertical distribution of $\mathrm{O}_{2}$ and $\mathrm{CO}_{2}$ and the $\mathrm{Fe}^{2+} / \mathrm{Fe}^{3+}$ ratio in the pore water suggest a predominance of organic matter oxidation in the sedimentary layer between 0.0 and $0.2 \mathrm{~m}$, with partially anaerobic mineralization of the mud sediments below $0.4 \mathrm{~m}$, especially in the coastal zone and inner shelf. However, the results indicate that there may be very significant differences between aerobic and anaerobic degradation of organic matter. Increases in trace element concentrations were observed in $\mathrm{Fe}$ reduction zones, indicating processes of desorption of Fe oxides and hydroxides and net mineralization of OM. The results of the incubation test indicated that $\Delta\left(\mathrm{CO}_{2 \mathrm{~T}}\right)>0$ for $\Delta\left(\mathrm{O}_{2}\right)<0$, suggesting that especially for the coastal zone and inner shelf the net mineralization rate has exceeded the net production rate of organic matter.

\section{COMPETING INTERESTS}

Authors have declared that no competing interests exist.

\section{REFERENCES}

1. Shokes RF. Rate-dependent distributions of lead-210 and interstitial sulfate in sediments, of the Mississippi River Delta. Texas: Department of Oceanography, Texas A\&M University, College Station, Report 76-1-T; 1976.

2. Aller RC, Mackin JE, Ullman WJ, Hou WC, Min TS, Cai JJ, et al. Early chemical digenesis, sediment-water solute exchange, and storage of reactive organic matter near the mouth of the Changjiang, East China Sea. Continental Shelf Research. 1985;4:227-251.

3. Shaw TJ, Gieskes JM, Jahnke RA. Early diagenesis in differing depositionalenviroments - the response of transitionmetals in pore water. Geochimica et Cosmochimica Acta. 1990;54(5):2331246.

4. Carman R, Rahm L. Early diagenesis and chemical characteristics of interstitial water and sediments in the deep deposition bottoms of the Baltic proper. Journal of Sea Research. 1997;37:25-47.

5. Ziebis W, Forster S. Impact of biogenic sediment topography on oxygen fluxes in permeable seabeds. Mar. Ecol. Prog. Ser. 1996;140:227-237.

6. Schulz HD. Quantification of early diagenesis: dissolved constituents in marine pore water. In: Schulz HD, Zabel $M$, editors. Marine Geochemistry. New York: Springer-Verlag; 2006.

7. Breitzke M. Physical Properties of Marine Sediments. In: Schulz HD, Zabel M, editors. Marine Geochemistry. New York: Springer-Verlag; 2006.

8. Siqueira G, Aprile F, Irion G, Marshall B, Braga $E$. Source and distribution of mercury in sediments of the Brazilian Amazon Continental Shelf with influence from fluvial discharges. American Chemical Science Journal. 2016;15:1-15.

9. Siqueira GW, Aprile FM. Distribution of total mercury in sediments from Amazon 
Continental Shelf - Brazil. Acta Amazônica. 2012;42:259-268. Portuguese.

10. Meade RH, Dunne JE, Richey U, Salate E. Storage and remobilization of suspended sediment in the lower Amazon river estuary. Nature. 1985;278:161-163.

11. Kuehl SA, DeMaster DJ, Nittroucr CA. Nature of sediment accumulation on the Amazon continental shelf. Continental Shelf Research. 1986;6:209-225.

12. Aller RC, Blair NE, Xia Q, Rude PD. Remineralization rates, recycling, and storage of carbon in Amazon shelf sediments. Continental Shelf Research. 1996;16(516):753-786.

13. Gibbs RJ. The bottom sediments of the Amazon Shelf and tropical Atlantic Ocean. Marine Geology. 1973;14(M)39-M45.

14. Donagema GK, Campos DVB, Calderano SB, Teixeira WG, Viana JHM, orgs. Manual of soil analyses methods. Rio de Janeiro: Embrapa Solos; 2011.

15. Jackson ML. Soil chemical analysis. Englewood Cliffs: Prentice-Hall; 1962.

16. Silva FC. Manual of chemical analyses of soils, plants and fertilizers. Brasília: Embrapa Solos - Embrapa Informática Agropecuária; 1999.

17. American Public Health Association (APHA), American Water Works Association (AWWA), Water Environment Federation (WEF). Standard methods for the examination of water \& wastewater. $22^{\text {nd }}$ ed. Washington, USA: APHA/AWWA/ WEF; 2012.

18. Mackin JE, Swider KT. Organic matter decomposition pathway and oxygen consumption in coastal marine sediments. J. Mar. Res. 1989;47:681-716.

19. Kielland J. Individual activity coefficients of ions in aquous solutions. Am. Chem. Soc. Jour. 1937;59:1675-1678.

20. Garrels RM, Thompson ME. A chemical model for sea water at $25^{\circ} \mathrm{C}$ and one atmosphere total pressure. Amer. J. Sci. 1962;260:57-66.

21. Nittrouer CA, Sharara MT, DeMaster DJ. Variations of sediment texture on the Amazon continental shelf. Journal of Sedimentary Petrology. 1983;53:179191.

22. Salomons W. Long-term strategies for handling contaminated sites end largescale areas. In: Salomons W, Stigliani WM, editors. Biogeodynamics of pollutants in soil and sediments: Risk assessments of delayed and non-linear responses. Environmental Science and Engineering Series. Berlin: Springer; 1995.

23. Förstner $U$. Sediment dynamics and pollutant mobility in rivers: An interdisciplinary approarch. Lakes \& Reservoirs: Research and Management. 2004;9:25-40.

24. Salomons W, Rooij NM de, Kerdijk H, Bril J. Sediments as a source for contaminants. Hydrobiologia. 1987;149:13-30.

25. Förstner $U$. Non-linear release of metals from aquatic sediments. In: Salomons W, Stigliani WM, editors. Biogeodynamics of pollutants in soils and sediments: Risk assessment of delayed and non-linear responses, Heidelberg: Springer Verlag; 1995.

26. Horowitz AJ. A primer on sediment-trace element chemistry. $2^{\text {nd }}$ ed. Chelsea, MI: Lewis Publishers Inc.; 1991.

27. Brown RM, McClelland NI. Up from chaos: The water quality index as an effective instrument in water quality management. Michigan: National Sanitation Foundation; 1974.

28. Froelich PN, Klinkhammer GP, Bender ML, Luedtke NA, Heath GR, Cullen D, et al. Early oxidation of organic matter in pelagic sediments of the eastern equatorial Atlantic: Suboxic diagenesis. Geochim. Cosmochim. Acta. 1979;43:1075-1090.

29. Sorensen J, Jorgensen BB, Revsbech NP. A comparison of oxygen, nitrate and sulfate respiration in coastal marine sediments. Microb. Ecol. 1979;5:105115.

30. Jorgensen BB, Sorensen J. Seasonal cycles of $\mathrm{O}_{2}, \mathrm{NO}_{3}^{-}$and $\mathrm{SO}_{4}^{-}$reduction in estuarine sediments: The significance of an $\mathrm{NO}_{3}{ }^{-}$reduction maximum in spring. Mar. Ecol. Prog. Ser. 1985;24:65-74.

31. Jorgensen BB, Revsbech NP. Oxygen uptake, bacterial distribution, and carbonnitrogen-sulfur cycling in sediments from the Baltic Sea-North Sea transition. Ophelia. 1989;31:29-49.

32. Jorgensen BB. The microbial sulfur cycle. In: Krumbein WE, editor. Microbial geochemistry. Oxford: Blackwell; 1983.

33. Aprile F, Darwich AJ, Siqueira GW, Ribeiro AA, Santos VC. Hydrological characterization of a whitewater lake at Amazon floodplain - Brazil. International 
Research Journal of Environment Sciences. 2013;2:44-53.

34. Vale C, Sundby B. The interactions between living organisms and metals in intertidal and subtidal sediments. In: Langston WY, Bebianno MY, editors. Metal metabolism in aquatic environments. London: Chapman \& Hall; 1998.

(c) 2019 Aprile et al.; This is an Open Access article distributed under the terms of the Creative Commons Attribution License (http://creativecommons.org/licenses/by/4.0), which permits unrestricted use, distribution, and reproduction in any medium, provided the original work is properly cited.

Peer-review history:

The peer review history for this paper can be accessed here: http://www. sdiarticle3.com/review-history/48586 